\title{
Temporolimbic Activation by Intracranial Electrical Stimulation
}

\author{
Jorge A. Ure, André Olivier, Luis Felipe Quesney, Mauricio Bravo, \\ Mónica Perassolo
}

\begin{abstract}
Background: To evaluate the results of intracranial electrical stimulation (ICES) as a pre-surgical tool in order to select the side of the operation in bitemporal lobe epilepsy (BTLE) patients who underwent depth electrode (DE) implantation. Methods: We reviewed the files of 77 medically intractable BTLE patients who underwent ICES with positive results through implanted DEs and then were under surgical treatment. One year or more after surgery, we evaluated the outcome. ICES was performed through: 1) Square-wave bipolar stimulation with symmetrical pulses of $60 \mathrm{~Hz}$ for $0.5 \mathrm{~ms}$ was delivered by a constant current Nuclear Chicago stimulator; 2) An initial intensity of $0.5 \mathrm{~mA}$, and subsequently progressively stronger currents at 1-2 and occasionally 3 or $4 \mathrm{~mA} ; 3$ ) The duration of a single stimulation was usually 5 seconds; 4) The volume of tissue effectively stimulated did not exceed 5 mm. Results: We obtained habitual auras or seizures (clinical responses, CRs) in 74 patients and after-discharges, ADs in 61 of them, according to Engel's classification for post surgery outcomes. If CRs or ADs were obtained by stimulation of only one temporal lobe the result of epilepsy surgery tended to be better (Engel classes I or II) when the operation was done on the same side of positive CRs (15 cases) or ADs (14 cases), and tended to be worse (Engel classes III or IV) when the ICES had provoked bilateral responses or when the side operated on was contra-lateral to positive CRs (33 cases) or ADs (28 cases). Statistical analyses were performed in order to test these results and we found better post-operative results when the resection took place in the same side of positive responses to ICES (CRs: $\chi^{2} 4.74$ and $\mathrm{p}=0.0295$; ADs: $\chi^{2} 7.57$ and $\mathrm{p}=0.0059$ ). Conclusion: In addition to other methods (PET, MRI and neuropsychology) presurgical ICES can provide useful data in the process of identifying the temporal lobe to be targeted for resection in BTLE patients.
\end{abstract}

RÉSUMÉ: Activation temporolimbique par stimulation électrique intracrânienne. Contexte : Le but de l'étude était d'évaluer les résultats de la stimulation électrique intracrânienne (SEIC) en tant qu'outil préopératoire afin de choisir de quel côté intervenir dans l'épilepsie bitemporale (EBT) chez les patients qui subissent une implantation d'électrodes profondes (EP). Méthodes : Nous avons révisé les dossiers de 77 patients atteints d'EBT réfractaire au traitement médical qui ont subi une SEIC avec de bons résultats et une chirurgie par la suite. Nous avons évalué les résultats un an ou plus après la chirurgie. La SEIC a été effectuée par : 1) une stimulation bipolaire à onde carrée avec pouls symétriques de $60 \mathrm{~Hz}$ pendant $0,5 \mathrm{~ms}$ délivrée par un stimulateur Nuclear Chicago à courant constant ; 2) une intensité initiale de $0,5 \mathrm{~mA}$ et par la suite des courants de plus en plus forts de 1 ou 2 et parfois 3 ou $4 \mathrm{~mA}$; 3) la durée d'une seule stimulation était habituellement de $5 \mathrm{~s} ; 4$ ) le volume de tissu stimulé efficacement n'excédait pas 5 mm. Résultats : Nous avons observé les auras ou les crises habituelles chez 74 patients (réponses cliniques, RC) et des post-décharges (PD) chez 61 d'entre eux, selon la classification d'Engel pour les résultats après la chirurgie. Si les RC ou les PD étaient obtenues par stimulation d'un seul lobe temporal, le résultat de la chirurgie pour épilepsie avait tendance à être meilleur (classe I ou II de Engel) quand la chirurgie portait sur le même côté que les RC positives (15 patients) ou les PD (14 patients) et pire (classe III ou IV de Engel) quand les SEIC avaient provoqué des réponses bilatérales ou quand le côté opéré était contra-latéral par rapport aux RC positives (33 patients) ou aux PD (28 patients). L'analyse statistique des données a démontré que les résultats postopératoires étaient meilleurs quand la résection était faite du même côté que les réponses positives à la SEIC (RC : X2 4,74 et $\mathrm{p}=0,0295$ ; PD X2 7,57 et p =0,0059). Conclusion : La SEIC avant la chirurgie peut fournir des données utiles à l'identification de la région temporale à cibler pour la résection chez les patients atteints d'EBT, en plus des autres méthodes (PET, IRM et neuropsychologie) couramment utilisées.

Can. J. Neurol. Sci. 2009; 36: 593-598

Intracranial electrical stimulation (ICES) is an approach to localize seizure onset in order to define the generating zone so that seizure freedom is likely if that zone is removed.

Intracranial electrical stimulation is a non-physiological stimulus capable of inducing typical electro-clinical seizures or auras (CRs) and/or after-discharges (ADs). It represents an important part of stereo-EEG investigations, through depth electrode recordings or subdural grid electrodes. It allows us to distinguish the epileptogenic zone from which the CRs and/ or ADs is reproducible immediately or with short latency after ICES. ${ }^{1}$
In this paper we summarize our observations of 77 BTLE patients who underwent intracranial electrical stimulation (ICES) using depth electrodes (DEs) in order to ascertain the

From the Departments of Electroencephalography (LFQ, MB) and Neurosurgery (AO), Montreal Neurological Institute and Hospital, Montréal PQ, Canada; Department of Neurology (JAU, MP), Borda and Moyano Hospitals, Buenos Aires, Argentina. ReCEIVEd April 21, 2009. Final Revisions Submitted May 25, 2009. Correspondence to: Jorge Ure, Department of Neurology, Borda Hospital, Ramón Carrillo 375, Buenos Aires, Argentina. 
site of onset of epileptic discharges. The objectives were: 1) to describe the site and type of provoked auras during ICES and to evaluate the relation between the DE studies and post-operative outcome seizure class 2) to evaluate the relation between the results of ICES and post-surgery follow-up. The hypotheses can be summarized as follows: When CRs and/or ADs similar to the auras or epileptic attacks were provoked using ICES, and the surgery was done on the indicated side, the post-resection results were positive.

\section{Material And Methods}

The patients were selected on the basis of clinical symptoms and ictal and interictal abnormalities on scalp electroencephalograms (EEG), being diagnosed as BTLE patients. We did this study with 77 patients, male and female, aged 14 - 53 years during the period 1972-2002 at the Montreal Neurological Institute, with the post-surgery follow-ups done 1-28 years later. We excluded three non-responsive patients for CRs (AD responses only) from the 77 patients on which the ICES was performed.

We used the Engel classification ${ }^{2}$ of outcomes with respect to epileptic seizures in order to evaluate the results of the surgery. According to this classification, seizure-free patients are ranked class I, rare seizures class II, patients who are slightly better class III, and those unaffected or worse after surgery are ranked class IV. We excluded from this study: 1) patients with extratemporal epilepsy; 2) patients unresponsive to ICES; 3) patients whose surgery was unsuccessful in removing the presumed epileptogenic tissue.

The present study is based upon DE investigations performed as part of the diagnostic evaluation prior to surgical treatment. Use of intracranial electrodes was indicated when monitoring with extracranial electrodes did not provide unequivocal localization of seizure onset. ${ }^{3}$

Spontaneous seizures did not occur frequently during these stimulation sessions. Stimulations, however, sometimes precipitated a seizure with a clinical and electrographic pattern that was often identical to the patient's habitual attacks. ${ }^{4}$

The DEs consisted of thin strands of wire with exposed contacts $5 \mathrm{~mm}$ apart that were introduced horizontally using stereotaxical coordinates. The stereotaxical procedures used to identify target structures have changed over the last three decades. In the early years, ventriculography and angiography were used. More recently, computer assisted methods of stereotaxic imaging by digital angiography, computerized tomography and magnetic resonance imaging have replaced the older methods. ${ }^{5,6}$

The configuration of the electrode placements was dependent upon the clinical problem and the results of previously done scalp EEGs. As described previously, ${ }^{7}$ the patients had bilateral temporal implantations of two or three electrode strands introduced on each side of the brain horizontally through the second temporal gyrus, with the deepest contacts aimed at the amygdala, the anterior and the mid hippocampus, and parahippocampus. The EEG was recorded on 16 or 32 channels using bipolar montages along each electrode strand. The patients were studied using virtually continuous video cable telemetry for periods of two to four weeks, during progressive anticonvulsant drug withdrawal. ${ }^{8,9}$
According to DE studies, when more than three seizures were recorded we classified our population into five groups: A) patients with ictal epileptic discharges always originating in the same region of the same side (confined discharges); B) patients where onset of seizures appeared in different regions of the same temporal lobe (unitemporal multiregional discharges); C) patients with bitemporal onset with marked lateral predominance (more than $80 \%$ of the attacks coming from the same side); D) patients with bitemporal onset with mild lateral predominance (more than $60 \%$ of the attacks coming from the same side); E) patients with bitemporal onset without lateral predominance.

Stimulations were applied sequentially through pairs of adjacent contacts in each electrode strand while recording the EEG, usually on 32 channels. Stimulation parameters were (for each side of the brain) : 1) square-wave bipolar stimulation with symmetrical pulses of $60 \mathrm{~Hz}$ applied during $0.5 \mathrm{~ms}$ delivered by a constant current Nuclear Chicago stimulator; 2) an initial intensity of $0.5 \mathrm{~mA}$, and subsequently progressively stronger currents of 1 - 2 and occasionally 3 or $4 \mathrm{~mA}$; 3 ) the duration of a single stimulation was usually five seconds and was followed in some instances by after-discharges of rhythmic activity that were different from the pre-stimulation activity and usually of higher amplitude lasting for at least one second, involving several channels, usually predominantly the recording from the stimulated electrode pair; 4) the volume of tissue effectively stimulated did not exceed $5 \mathrm{~mm}$ in diameter, since many CRs or ADs could no longer be elicited by stimulating at a distance of 5 $\mathrm{mm}$ from the effective site; 5) each stimulated site was restimulated at the higher intensities with intervals between each stimulation of at least 20 minutes. Re-stimulation of the same site at a shorter interval of one to two minutes. was performed when a positive CR was elicited, usually without warning, to confirm that the response was genuine. The duration of stimulation in the few instances in which it was varied seemed to affect the responses very little. In many instances, when the intensity was raised above the threshold value for eliciting a given clinical response, no new clinical features were elicited but the likelihood of inducing ADs was increased.

The patients were observed by a clinical neurophysiologist, and their behaviour was recorded on a video-audio tape. They were asked to report any experiences during these stimulations. The responses were validated by warning without stimulation or stimulation without warning, but very few patients reported false positive responses. A clinical phenomenon elicited by ICES at a particular site was usually reproduced at the same site during subsequent stimulations at increased current intensities and these repetitions helped to validate our observations. The ICES studies were performed in day-long sessions at the end of the period of EEG monitoring, usually when all anticonvulsant medications had been withdrawn.

Seizure outcome was documented by periodical clinical visits to the Hospital and also by phone contact.

Chi-square methods were used to test statistically the proposed hypotheses choosing a 5\% significance level.

\section{RESULTS}

\section{1 - The site and type of provoked auras or seizures during ICES}

We obtained the habitual auras or seizures in 74 patients who underwent ICES. Location of CRs (in general more than one site 
Table 1: Different types of auras from 74 patients obtained through ICES and the sites of 131 responses from the limbic structures

\begin{tabular}{l|c|c|c|c|c|c}
\hline \multirow{2}{*}{ Types of auras } & \multicolumn{5}{|c}{ Sites of responses } \\
\cline { 2 - 7 } & RA & RB & RC & LA & LB & LC \\
\hline Epigastric and chest & 16 & 11 & 5 & 16 & 16 & 3 \\
sensations & & & & & & \\
\hline Head sensations & 4 & 2 & 3 & 3 & 3 & 1 \\
\hline Dejá vù & 7 & 6 & 2 & 4 & 2 & 2 \\
\hline Strangeness & 1 & 1 & 0 & 0 & 0 & 0 \\
\hline Fear & 1 & 2 & 1 & 5 & 2 & 1 \\
\hline Laughing & 1 & 1 & 1 & 1 & 0 & 0 \\
\hline Dizziness & 3 & 1 & 0 & 2 & 1 & 0 \\
\hline
\end{tabular}

RA: right amygdala; RB: right hippocampus; RC: right parahippocampus; LA: left amygdala; LB: left hippocampus; LC: left parahippocampus; Note that "Dejá vù" showed a marked predominance from right hemisphere sites (15/8), whereas "Fear" showed a predominance from left hemisphere sites (8/4).

for each patient) in the temporal mesial structures was as follows: left amygdala 31, right amygdala 33, left hippocampus 24 , right hippocampus 24, left parahippocampus 7 and right parahippocampus 12 (see Table 1), which accords with Feindel's statements ${ }^{10}$ about the predominance of the amygdala in such responses. There were no significant differences between left and right structures, as has been pointed out by Palmini and Gloor. ${ }^{11}$ As can be seen, it is very difficult to localize exactly the punctual origin of such auras because more than one structure can be involved (131 sites of CR in 74 patients, Table 1).

We found epigastric and chest sensations (pressure, feeling of heat, sensation rising from the stomach to the chest) in 67 sites from 44 patients. These sensations were sometimes purely visceral or accompanied by pleasant (five patients) or unpleasant emotions (four patients). Similar sensations in the head were reported in 16 sites from ten patients, déja vù in 23 sites from 14 patients, strangeness in 2 sites from one patient, laughing in 4 sites from another, and dizziness in seven places from nine patients.

According to Gloor's clinical reports funny feelings in the low abdominal region in one female patient was explained "like wanting a man or just having intercourse". In another patient it was "grandiose feeling of well being". Other patient complained it was "like butterflies in my stomach", and this sensation was associated with "something imminent that is going to happen, something happening in one second" (perhaps an unconscious perception of an ongoing seizure). Some patients who experienced "head sensations" maintained that "all over my face there is a sound of music". Two patients experienced flashback memories, one of them saying "I am in a cottage on the lake, feeling like a rainy day on my shoulder". Two others complained of an "indescribable vague feeling" and a "floating feeling". Finally, one patient spoke of a "far away feeling seeing two famous comic strips", or merely "thinking of these famous comics".

\section{2 - Relation between groups according to DE studies and outcome seizure classification}

The post-operative outcome was best in Group A (50\% of the patients were seizure-free or had rare seizures), followed by Group B (40\%), Group C (37.5\%) Group E (30\%) and Group D (27\%).

In groups $\mathrm{D}$ and $\mathrm{E}$ the patients tended to range between the two extremes (class I or class III-IV more often than class II), depending on the eventual occurrence of the post surgical inactivation of a secondary dependent focus in the contralateral side (running-down phenomenon). ${ }^{12}$

\section{3 - Relation between the results of the ICES and the subsequent post-surgery outcome}

a) Clinical responses (CRs), $\mathrm{N}=74$

(1) Best results were observed (seizure-free in 14/28 cases) when CRs were obtained by stimulation of only one temporal lobe and surgery was done on that side (15 Engel class I \& II, 13 Engel class III \& IV ). Least satisfactory results were observed when the surgery was done contralaterally to the CRs (6 Engel class I \& II, 13 Engel class III \& IV).

(2) Where CRs were obtained from both temporal lobes, the outcomes of resection tended to be classes III or IV (20 cases) rather than classes I or II (7 cases).

With these results we propose the hypotheses can be tested using a chi-square method. The resulting $\chi^{2}$ statistic, where the subscript indicates the degrees of freedom, was 4.89 with a pvalue (probability of a $\chi^{2}$ value greater than the calculated) of 0.0866 . This $\mathrm{p}$-value superior to the significance value specified as 0.05 leads to the conclusion that the homogeneity cannot be rejected. If the categories "CRs on both sides" and "CRs/Surgery opposite sides" are conflated in one named "CRs bilateral and CRs/Surgery opposite sides", the hypothesis now gives a $\chi^{2}$ value of 4.74 with one degree of freedom and a p-value of 0.0295 which is less than the fixed significance level of $5 \%$. Therefore, the homogeneity is rejected (see Table 2).

b) Afterdischarges (ADs), $\mathrm{N}=61$

There were 16 cases with CRs without ADs, and 3 cases of ADs without CRs.

Taking into consideration the side of origin of ADs we obtained the same results as we found with CRs: when the ADs were registered on the same side of the following operation the outcome tended to be classes I-II (14/21 cases), and when they appeared contralateral or bilateral the outcome tended to be classes III-IV (28/40 cases).

If the categories "ADs on both sides" and "ADs/Surgery opposite sides" are conflated into one named "ADs bilateral and $\mathrm{AD} /$ Surgery opposite sides", the hypothesis gives $\chi^{2}$ as 7.57 with one degree of freedom and a probability or $p$-value equal to 0.0059 , which refutes the homogeneity. It is to be observed that the category "ADs bilateral and AD/Surgery opposite sides" has the highest frequency for the Engel classes III an IV, while the 
Table 2: Relation between the results of the ICES-CRs and the follow-up after surgery

\begin{tabular}{c|c|c|c}
\hline \multirow{2}{*}{$\begin{array}{c}\text { SIDE OF } \\
\text { CRs/SURGERY }\end{array}$} & \multicolumn{2}{|c|}{$\begin{array}{c}\text { ENGEL'S POST- } \\
\text { OPERATIVE } \\
\text { CLASSIFICATION }\end{array}$} \\
\cline { 2 - 3 } & $\mathbf{I} \&$ II & III \& IV & TOTAL \\
\hline CRs on both sides & 7 & 20 & $\mathbf{2 7}$ \\
\hline $\begin{array}{c}\text { CRs/Surgery same side } \\
\begin{array}{c}\text { CRs/Surgery opposite } \\
\text { sides }\end{array}\end{array}$ & 15 & 13 & $\mathbf{2 8}$ \\
\hline Total & $\mathbf{2 8}$ & 13 & 19 \\
\hline
\end{tabular}

category "ADs/Surgery same side" has the highest frequency for Engel I and II. In two cases there were conflicting results between the side of CRs and the opposite side where ADs were obtained. In these cases the surgery was done on the CRs localizing side and the results in both cases fall in Engel's class IV, perhaps indicating that the localizing value of lateralized CRs disappears when ADs are elicited only in the opposite side. In the retrospective analyses we didn't know the criterion that was used in order to choose the side of the resection.

\section{DISCUSSION}

Basic information was lacking for establishing suitable parameters of the electrical stimulus. The current-density fields in various nonhomogeneous conductors with various electrode orientations, the effect of different waveforms, frequencies, durations, train duration, and current and voltage, in addition to the quality of the electrodes are all factors which must be considered before one may be sure that the results obtained upon electrical stimulation of the brain are valid ${ }^{13}$. The ease of provoking ADs was not necessarily related to the induction of the patient's aura. After-discharges can occur without any clinical concomitant and vice-versa. We will not discuss here the problem of thresholds for elicited ADs. There are many discrepancies in previous work on this point. ${ }^{14,15}$

Using ICES, Bernier et $\mathrm{al}^{15}$ found a more than $90 \%$ concordance between spontaneous and induced auras or seizures with a single unitemporal focus, but less concordance with multiple foci. It is possible to use trains (ICES) or single-pulse electrical stimulation (SPES) ${ }^{16}$ The value of ICES diminishes in frontal epilepsy patients, because it is more difficult to make the distinction between epileptic and non-epileptic network responses. Valentin et $\mathrm{al}^{17}$ found it useful to separate early from delayed responses in such patients. Whereas early responses were seen in most regions and seem to be a normal response of the cortex to SPES, distribution of delayed responses was significantly associated with the regions where seizure onset occurred. They did only SPES, and concluded it could be an important presurgical tool in order to identify frontal epileptogenicity. ${ }^{18}$ Neuropathological examination showed structural abnormalities in the abnormal SPES areas in 26 of 29 patients in whom these regions were resected, despite the absence of clear MRI abnormalities in nine of these patients. Valentin et $\mathrm{al}^{19}$ have extended these concepts to the temporal region.

Bancaud et $\mathrm{al}^{20}$ pointed out that both medial and lateral temporal structures are involved in experiential phenomena obtained by ICES with special sensitivity in the anterior hippocampus, amygdala, and superior temporal gyrus.

Halgren et $\mathrm{al}^{21}$ had published a review of 36 patients who underwent ICES in a comprehensive programme for the study and treatment of partial epilepsy. They maintained that electrical stimulation of the human temporal lobe may evoke sensations, emotions or cognitions, but the responses showed a marked variability between different patients. Their results were not specifically marks of epileptic responses since stimulation of the surface and depths of the temporal lobes in non-epileptic patients may also result in visual hallucinations. ${ }^{22}$ According to Halgren et $\mathrm{al}^{21}$ there was no evidence that any of the phenomena were associated specifically with stimulation of either the dominant or non-dominant hemisphere, because every mental phenomenon occurs within a total experience that probably has a diffuse network representation.

Schulz et $\mathrm{al}^{23}$, using stimulation by subdural electrodes found frequent overlap of the stimulation-induced auras zone with the epileptogenic lesion and the EEG seizure onset zone. Concerning the depth electrode investigations with ICES in patients with bitemporal epileptiform abnormalities, So et $\mathrm{al}^{14}$ concluded no reliable $\mathrm{AD}$ threshold asymmetry was found on electrical stimulation of homologous mesial temporal lobe structures. When an aura occurred on stimulation of only one side, it was more likely to be concordant with the side of exclusive or predominant ictal onset, as it can be seen in our present study. As in this study, the lack of a strong predominance of one side of the brain in respect to the onset of seizures in DE studies was found to be a factor of poor postsurgical outcome ${ }^{24}$. Positron emission tomography (PET) and magnetic resonance imaging (MRI), when pointing to the side opposite to the result of DE studies may indicate a poor prognosis, according to Benbadis et al..$^{25}$

According to the literature, ICES appeared most advantageous when it provoked CRs which are similar or almost similar to those the patient suffered during an epileptic attack. Clinical responses have more value when there is a habitual aura or seizure, particularly if it is an experiential phenomenon (dreamy state with duplication of consciousness), because simple sensorial or motor responses can be physiological in nature.

Gloor et $\mathrm{al}^{7}$ have studied "the experiential phenomena" elicited by means of ICES in order to determine if they come from the mesial or the lateral aspect of the temporal lobe and concluded that the leading role is played by the limbic structures. Anatomically they are connections between the amygdala and hippocampus with the multimodal association cortices. ${ }^{26}$

The experiences were described previously by Penfield ${ }^{27}$, Gloor $^{7}$, Halgren and Chauvel ${ }^{28}$ and Bancaud et $\mathrm{al}^{20}$ Ferguson et 
$\mathrm{al}^{29}$ have found similarities between the responses to ICES in patients with temporal lobe epilepsy and the mental content of psychotic states, spontaneous seizures and/or dreams.

As we said previously, some misperceptions (sensations), memory flashbacks (cognition) or strange feelings (emotions) are similar to what the patients experienced during their attacks. It was hypothesized by Gloor $^{30}$ that during ICES the experiences appeared by disruption of the normal activation of the mesial (and/or lateral) structures of the temporal lobe. The ongoing activity which supports the consciousness stream, working memory for example, can be altered during the stimulation of the mesial structures of the temporal lobe. The relative inexcitability that often occurred in the more damaged sites can be caused by the lack of neurons in patients affected by hippocampal atrophy.

Holmes et $\mathrm{al}^{31}$, found a portion of surgical candidates with good prognoses post-operative from a group of patients with bitemporal interictal epileptiform patterns on scalp EEG that can be selected through ictal recordings made during DE studies providing consistent information about strictly unilateral basaltemporal epileptiform abnormalities when the other data (MRI, neuropsychology) are not discordant. Jenssen et $\mathrm{al}^{32}$ emphasized the value of non-invasive testing when independent bitemporal seizures occurred in the scalp EEG but PET and MRI show focal abnormalities at the same region. They found that if there is a history of febrile convulsions and non-invasive (PET, MRI) test results point to abnormality in the same temporal lobe no further evaluation would be needed.

We could investigate the side of onset of epileptic discharges using DE recording of at least three seizures during video monitoring telemetry. It was a useful tool in order to select candidates for surgery in patients who had ictal bitemporal independent epileptiform abnormalities in telemetry with scalp EEG. We have classified the results of ictal recordings in five groups: Group A with the most localized unitemporal alteration, Group B still unitemporal but poorly localized, Group C with bitemporal onset and strong predominance of one side, Group D with bitemporal onset and mild predominance of one side, and Group E with no predominance or minimal predominance, in fact mainly bitemporal onset of the seizures. We found best postsurgical outcome in patients of Group A, and progressively worse outcomes in the other groups from B to D. In Groups D and E, six patients (28\%) did well after surgery (running-down phenomenon).

The possibility of predicting good or poor outcomes improved with ICES when it was possible to localize CRs and ADs on only one side of the temporal lobes. The persistence of auras could be attributable to the activity of the contralateral focus in the non-operated side, or conversely, persistence of epileptic activity in the remaining tissue of the excised side. Three patients showed a tendency to increase seizures after a latent post-surgical period and these fits arose from the nonoperated side (running-up phenomenon) ${ }^{33}$, one of them having a post-encephalitic brain.

Finally one must bear in mind that epilepsy is a dynamic disease and the neuronal networks can exhibit different functional states. For example, there can be a secondary dependent focus contralateral to the operation with runningdown behaviour, or conversely worsening of non-operated focus, in the same side of the operation (small excision) or in the other side (contralateral independent focus) or epileptogenesis de novo after a silent period (running-up behaviour). Chkhenkeli et $\mathrm{al}^{34}$ suggest the establishment of functional interrelations between two epileptic foci at an early phase of seizures. A mutually suppressive relationship is one of the variants of the interaction of symmetric epileptic foci. Some epilepsy surgery failures may be a result of post-surgical activation of the intact focus. Another functional interrelation was documented by Inoue et $\mathrm{al}^{35}$, who found electrical stimulation of the contralateral mesial temporal structure was prone to induce an ipsilateral seizure pattern in mesial temporal lobe epilepsy.

The postsurgical follow-up may also be influenced by many other extra-surgical factors such as other illnesses, appearance of new diseases, use or abuse or abrupt withdrawal of antiepileptic drugs, psychosocial factors, etc. Salanova et $\mathrm{al}^{36}$ have published an interesting analysis of failures and the role of re-operation. They reported a $57 \%$ rate of success (seizure-free) following reoperation. According to Bertram ${ }^{37}$, is still very difficult to determine the precise site of seizure onset in temporal lobe epilepsy patients, because in some cases is possible there may not be such a precise point. Intracranial electrical stimulation can also apply in order to reduce seizures in refractory adult epilepsy ${ }^{38}$.

At Montreal Neurological Institute, we reviewed the files of 74 patients suffering from BTLE by mean of scalp EEGs (interictal and ictal epileptiform discharges) and clinical symptoms, who underwent DE studies and ICES through stereotaxically chronically implanted intracerebral electrodes in order to evaluate the lateralization of epileptic discharges for presurgical reasons. Discharges appeared more unilateral (Group A) or bilateral (Group E), ranging in five categories (from Group A to Group E). The best post-surgical results were found in Group A, followed by groups B, C, E and D. We found induced clinical responses habitual to their auras or epileptic attacks in 74 and afterdischarges in 61 patients. The CRs from the limbic structures were localized mainly in the left or right amygdala (49\%), the left or right hippocampus (37\%), and the left or right parahippocampus $(14 \%)$. There were no significant differences between left and right side on the same structure.

By taking into account the lateralization of the CRs and the ADs induced by ICES, we found a good predictive value of outcome. The lateralization of such responses had good predictive value for $65-69 \%$ of these patients who were operated with a follow-up at least one year post-op. By taking into account the lateralization of the CRs and the ADs induced by ICES, we found a good predictive value of outcome. These outcomes tend to be better (Engel class I \& II) when the side of the induced CRs or ADs was the same side that was operated, and tends to be worse (Engel class III \&IV) when the operation was done in the contralateral side or the responses were bilateral. Statistical analyses were performed in order to test these results and we found better post-operative results when the resection took place in the same side of positive responses to ICES (CRs: $\chi^{2} 4.74$ and $\mathrm{p}=0.0295$; ADs: $\chi^{2} 7.57$ and $\mathrm{p}=0.0059$ ).

\section{ACKNOWLEDGMENT}

The authors thank Dr. Frederick Andermann and Dr. Francois Dubeau from the Montreal Neurological Institute, for giving us 
wise advise and for doing previous studies in this field, and Dr. Marta Zanelli, from CONICET, Buenos Aires, for doing the statistical analysis.

\section{REFERENCES}

1. Gombi R, Velok G, Hullay J. The value of electrostimulation in epileptic focus localization. Acta Neurochir (Wien). 1976;23 Suppl:15-20.

2. Engel J Jr. Outcome with respect to epileptic seizures. In: Engel J Jr, editor. Surgical treatment of the epilepsies. New York: Raven Press; 1987. p. 553-71.

3. Quesney LF, Gloor P. Localization of epileptic foci. Electroencephalogr Clin Neurophysiol Suppl. 1985;37:165-200.

4. Fish DR, Gloor P, Quesney LF, Olivier A. Clinical responses to electrical brain stimulation of the temporal and frontal lobes in patients with epilepsy. Pathophysiological implications. Brain. 1993;116(2):397-414.

5. Olivier A, de Lotbinière A. Stereotactic techniques in epilepsy. In: Tasker RR, editor. Stereotactic surgery. Neurosurgery: state of the arts reviews, Vol 2, No. 1. Philadelphia: Hanley and Belfus; 1987. p. 257-85.

6. Olivier A, Marchand E, Peters T, Tyler J. Depth electrode implantation at the Montreal Neurological Institute and Hospital. In: Engel J Jr, editor. Surgical treatment of the epilepsies. New York: Raven Press; 1987. p. 595-601.

7. Gloor P, Olivier A, Quesney LF, Andermann F, Horowitz S. The role of the limbic system in experiential phenomena of temporal lobe epilepsy. Ann Neurol. 1982;12(2):129-44.

8. Ives JR, Gloor P. A long term time-lapse video system to document the patient's spontaneous clinical seizure synchronized with the EEG. Electroencephalogr Clin Neurophysiol. 1978;45(3): 412-16.

9. Gotman J, Ives JR, Gloor P, Quesney LF, Bergsma P. Monitoring at the Montreal Neurological Institute. Electroencephalogr Clin Neurophysiol Suppl. 1985;37:327-40.

10. Feindel W. Response patterns elicited from the amygdala and deep temporoinsular cortex. In: Sheer D, editor. Electrical stimulation of the brain: an interdisciplinary survey of neurobehavioral integrative systems. Austin, TX: University of Texas Press; 1961. p. 519-32.

11. Palmini A, Gloor P. The localizing value of auras in partial seizures: a prospective and retrospective study. Neurology. 1992;42(4): 801-8.

12. Salanova V, Andermann F, Rasmussen T, Olivier A, Quesney L. The running down phenomenon in temporal lobe epilepsy. Brain. 1996;119(3):989-96.

13. Mickle WA. The problems of stimulation parameters. In: Sheer D, editor. Electrical stimulation of the brain: an interdisciplinary survey of neurobehavioral integrative systems. Austin, TX: University of Texas Press; 1961.p. 67-73.

14. So N, Gloor P, Quesney LF, Jones-Gotman M, Olivier A, Andermann F. Depth electrode investigations in patients with bitemporal epileptiform abnormalities. Ann Neurol. 1989;25(5):423-31.

15. Bernier GP, Richer F, Giard N, Bouvier G, Mercier M, Turmel A, et al. Electrical stimulation of the human brain in epilepsy. Epilepsia. 1990;31(5):513-20.

16. Kahane P, Tassi L, Francione S, Hoffmann D, Lo Russo G, Munari C. [Electroclinical manifestations elicited by intracerebral electrical stimulation "shocks" in temporal lobe epilepsy]. Neurophysiol Clin. 1993;23(4):305-26. French.

17. Valentin A, Anderson M, Alarcón G, Seoane JJ, Selway R, Binnie $\mathrm{CD}$, et al. Responses to single pulse electrical stimulation identify epileptogenesis in the human brain in vivo. Brain. 2002; 125(8): 1709-18.

18. Valentin A, Alarcón G, Garcia-Seoane JJ, Lacruz ME, Nayak SD, Honavar M, et al. Single-pulse electrical stimulation identifies epileptogenic frontal cortex in the human brain. Neurology. 2005;65(3):426-35.
19. Valentin A, Alarcón G, Honavar M, Garcia-Seoane JJ, Selway RP, Polkey CE, et al. Single pulse electrical stimulation for identification of structural abnormalities and prediction of seizure outcome after epilepsy surgery: a prospective study. Lancet Neurol. 2005;4(11):718-26.

20. Bancaud J, Brunet-Bourgin F, Chauvel P, Halgren E. Anatomical origin of déjà vu and vivid 'memories' in human temporal lobe epilepsy. Brain. 1994;117(1):71-90.

21. Halgren E, Walker RD, Cherlow DG, Crandall PH. Mental phenomena evoked by electrical stimulation of the human hippocampal formation and amygdala. Brain. 1978;101(1): 83-117.

22. Ishibashi T, Hon H, Endo K, Sato T. Hallucinations produced by electrical stimulation of the temporal lobes in schizophrenic patients. Tohoku J Exp Med. 1964; 82:124-39.

23. Schulz R, Luders HO, Tuxhorn I, Ebner A, Holthausen H, Hoppe $\mathrm{M}$, et al. Localization of epileptic auras induced on stimulation by subdural electrodes. Epilepsia. 1997;38(12):1321-9.

24. So N, Olivier A, Andermann F, Gloor P, Quesney LF. Results of surgical treatment in patients with bitemporal epileptiform abnormalities. Ann Neurol. 1989;25(5):432-9.

25. Benbadis S, So N, Antar MA, Barnett GH, Morris HH. The value of PET scan (and MRI and Wada Test) in patients with bitemporal epileptiform abnormalities. Arch Neurol. 1995;52(11):1062-8.

26. Halgren E, Marinkovic K. Neurophysiological networks integrating human emotions. In: Gazzaniga MS, editor. The Cognitive Neurosciences. Cambridge, MA: MIT Press; 1994. p. 1137-51.

27. Penfield W. The mystery of the mind. A critical study of consciousness and the human brain. Princeton, NJ: Princeton University Press; 1975.

28. Halgren E, Chauvel P. Experiential phenomena evoked by human brain electrical stimulation. In: Devinsky O, Beric A, Dogali M, editors. Electrical and magnetic stimulation of the brain and spinal cord. New York: Raven Press; 1993. p. 123-40.

29. Ferguson SM, Rayport M, Gardner R, Kass W, Weiner H, Reiser M. Similarities in mental content of psychotic states, spontaneous seizures, dreams, and responses to electrical brain stimulation in patients with temporal lobe epilepsy. Psychosom Med. 1969;31 (6):479-98.

30. Gloor P. Experiential phenomena of temporal lobe epilepsy. Facts and hypotheses. Brain. 1990;113(6):1673-94.

31. Holmes MD, Dodrill CB, Ojemann GA, Wilensky AJ, Ojemann LM. Outcome following surgery in patients with bitemporal interictal epileptiform patterns. Neurology. 1997;48(4):1037-40.

32. Jenssen S, Liporace J, Nei M, O'Connor MJ, Sperling MR. Value of non-invasive testing when there are independent bitemporal seizures in the scalp EEG. Epilepsy Res. 2006;68(2):115-22.

33. Bravo M, Quesney LF, Ure JA, Olivier A, Dubeau F, Bernasconi A, et al. Running-up phenomenon in temporal lobe epilepsy. Abstracts of the 24th International Epilepsy Congress; 2001; Buenos Aires, Argentina. Epilepsia. 2001;42Suppl. 2:98.

34. Chkhenkeli SA, Towle VL, Lortkipanidze GS, Spire JP, Bregvadze ESh, Hunter JD, et al. Mutually suppressive interrelations of symmetric epileptic foci in bitemporal epilepsy and their inhibitory stimulation. Clin Neurol Neurosurg. 2007;109(1): 7-22.

35. Inoue $\mathrm{Y}$, Mihara T, Tottori T, Seino M. Electrical stimulation of the contralateral mesial temporal structure induces an ipsilateral seizure pattern in mesial temporal lobe epilepsy. Epilepsia. 1999;40(11):1602-9.

36. Salanova V, Markand O, Worth R. Temporal lobe epilepsy: analysis of failures and the role of reoperation. Acta Neurol Scand. 2005;111(2):126-33.

37. Bertram EH. Temporal lobe epilepsy: Where do the seizures really begin? Epilepsy Behav. 2009; 14: 32-7.

38. Sun F, Morrell M, Wharen R Jr. Responsive cortical stimulation for the treatment of epilepsy. Neurotherapeutics. 2008;5(1): 68-74. 